\title{
Early outcomes of percutaneous pulmonary valve implantation using the Edwards SAPIEN XT transcatheter heart valve system
}

Nikolaus A. Haas ${ }^{1,2}$, Ronald Giacomo Carere ${ }^{3}$, Oliver Kretschmar ${ }^{4}$, Eric Horlick ${ }^{5}$, Josep Rodés-Cabau ${ }^{6}$, Daniël de Wolf 7, Marc Gewillig ${ }^{8}$, Michael Mullen ${ }^{9}$, Anja Lehner ${ }^{1}$, Cornelia Deutsch ${ }^{10}$, Peter Bramlage ${ }^{10}$, Peter Ewert ${ }^{11}$

1. Department of Pediatric Cardiology and Pediatric Intensive Care, LMU München, Germany. Email: nikolaus.haas@med.uni-muenchen.de; anja.lehner@med.uni-muenchen.de

2. Centre for Congenital Heart Defects, Heart and Diabetes Centre Bad Oeynhausen, Ruhr University Bochum, Bad Oeynhausen, Germany

3. St. Paul's Hospital, Vancouver, Canada. Email: rcarere@providencehealth.bc.ca

4. University Children's Hospital Zurich and University Hospital Zurich, Switzerland. Email: oliver.kretschmar@kispi.uzh.ch

5. Toronto General Hospital, Toronto, Canada. Email: eric.horlick@uhn.ca

6. Quebec Heart and Lung Institute, Laval University, Quebec City, Quebec, Canada. Email: josep.rodes@criucpq.ulaval.ca

7. Gent University Hospital, Belgium. Email: daniel.dewolf@uzgent.be

8. ZU Gasthuisberg, Belgium. Email: marc.gewillig@uzleuven.be

9. The Heart Hospital, London, UK. Email: michael.mullen@uclh.nhs.uk

10. Institute for Pharmacology and Preventive Medicine, Cloppenburg, Germany. Email: cornelia.deutsch@ippmed.de; peter.bramlage@ippmed.de

11. Department of Pediatric Cardiology and Congenital Heart Disease, German Heart Centre Munich, Technical University Munich, Germany. Email: ewert@dhm.mhn.de

\section{Correspondence}

Prof. Dr. Nikolaus A. Haas

Department of Pediatric Cardiology and Pediatric Intensive Care, Medical Hospital of the University of Munich, Marchioninistrasse 15, 81377 München, Germany

Tel.: +49 89 440073941; Fax: +4989 440073943; email: nikolaus.haas@med.uni-muenchen.de 


\begin{abstract}
Funding
This work was supported by an unrestricted educational research grant that was provided by Edwards Lifescience, Nyon, Switzerland to IPPMed.
\end{abstract}

\title{
Competing Interests
}

Peter Bramlage is the representative of the Institute for Pharmacology and Preventive Medicine (IPPMed), Cloppenburg, Germany.

Keywords: pulmonary valve, congenital heart disease, percutaneous pulmonary valve implantation, SAPIEN XT

Article type: Clinical Paper

Words: 3,349

Abstract: 237

Figures: 0 Tables: 4 Supp. tables: 1

Supp. figures: 2

References: 18

Version: 14.06.2017 
ABSTRACT

Background: Patients with congenital or acquired heart defects affecting the pulmonary valve and right ventricular outflow tract (RVOT) commonly require multiple surgical interventions, resulting in significant morbidity. A less invasive alternative is percutaneous pulmonary valve implantation (PPVI). Though studies have previously reported the safety and efficacy of the early generation transcatheter heart valves (THVs), data on more recent devices are severely lacking.

Methods and Results: We performed a multinational, multicentre, retrospective, observational registry analysis of patients who underwent PPVI using the Edwards SAPIEN XT THV. Of the 46 patients that were enrolled, the majority had tetralogy of Fallot as the underlying diagnosis (58.7\%), and stentless xenograft as the most common RVOT anatomy (34.8\%). Procedural success rate was high (93.5\%), with a low frequency of periprocedural complications and adverse events $(6.5 \%$ and $10.9 \%$, respectively). At 30 days post-procedure, NYHA class had improved significantly $(90.6 \%$ were at NYHA I or II). The rate of moderate/severe pulmonary regurgitation had decreased from $76.1 \%$ at baseline to $5.0 \%$ at 30 days, and the calculated peak systolic gradient had decreased from 45.2 (SD \pm 21.3) $\mathrm{mmHg}$ to $16.4(\mathrm{SD} \pm 8.0) \mathrm{mmHg}$, with these values remaining low up to 2 years.

Conclusions: The data suggest the efficacy and safety of the SAPIEN XT THV in PPVI in common anatomies in patients with conduits, as well as those with native pulmonary valves or transannular patches. Continued data collection is necessary to verify long-term findings.

Clinicaltrials.gov identifier: NCT02302131

Keywords: pulmonary valve, congenital heart disease, percutaneous pulmonary valve implantation, SAPIEN XT 


\section{INTRODUCTION}

Malfunctioning pulmonary valves and alterations of the right ventricular outflow tract (RVOT) are frequent in many congenital heart defects. Typical examples include Tetralogy of Fallot (ToF), double outlet right ventricle (DORV), pulmonary stenosis (PS), pulmonary atresia (PA), truncus arteriosus (TA), transposition of the great arteries (TGA) with PS (Rastelli's Operation), absent pulmonary valve syndrome (Miller-Lev-Paul), and the Ross Procedure for aortic valve disease.

Surgical correction involves the repair or replacement of the native RVOT using biological valves such as homografts, bioprostheses, or xenografts. These valve corrections frequently become dysfunctional within 3 to 20 years after the primary intervention, depending on patient's age and size. This results in the requirement for a further pulmonary valve replacement procedure. An emerging, less invasive treatment option that aims to reduce the considerable morbidity associated with repeat operations is percutaneous pulmonary valve implantation (PPVI). ${ }^{1,2}$

Until recently, the Medtronic Melody and Edwards SAPIEN transcatheter heart valves (THVs) were the only registered devices for this purpose, with the Melody valve available in diameters of 18,20 , and $22 \mathrm{~mm}$, and the Edwards SAPIEN valve being available in diameters of 23 and $26 \mathrm{~mm} \cdot{ }^{3-6}$ On-going developments in THV design have led to the next generation SAPIEN XT being available in sizes of 20 , 23, 26, and $29 \mathrm{~mm}$ (for further details see Supplementary Table 1); however, there is a clear need for data on the new valve technology. For this reason, we began to retrospectively collect the available data on SAPIEN XT implants in the pulmonic position, and to follow the identified patients within the structured environment of a multicentre registry. We aimed to describe patient experiences, and to document the feasibility and safety of using the SAPIEN XT THV for PPVI. 


\subsection{Centres}

Based on information provided by the core group of participating centres and Edwards Lifesciences, we estimated that approximately 23 centres globally (excluding the United States) had performed at least one PPVI using SAPIEN XT technology, with an approximate total of 92 patients receiving the valve (estimated range 77 to 120). We approached all 23 centres in November 2014 to initiate data collection. These included centres in Europe (Belgium, Switzerland, Germany, Netherlands, UK, Sweden, Italy, France), the Middle East (Israel, Saudi Arabia), North America (Canada), and Australia.

\subsection{Patients}

Patients with a clinical indication for PPVI who had undergone or were undergoing the procedure using the SAPIEN XT THV were eligible, provided that they supplied signed data release and informed consent. So as to cover the broadest possible spectrum of patients undergoing PPVI, no exclusion criteria were stipulated. 


\subsection{Endpoints}

The endpoints of this registry were selected in order to evaluate the feasibility and safety of implanting a SAPIEN XT THV in the pulmonic position. The procedural and clinical outcome data collected were based on the standards of care for PPVI at each individual participating site. Examinations may include (but are not limited to) physical assessments, ECG, exercise testing, laboratory results, X-rays, angiograms, CT/MRI scans, and transthoracic and/or transoesophageal echocardiography.

Short-term outcomes included right ventricular (RV) and pulmonary artery (PA) pressures, maximum flow velocity RVOT, degree of pulmonary regurgitation, peak gradients, procedural success, and length of hospitalisation (from admission to discharge). Long-term outcomes included changes in New York Heart Association (NYHA) class; peak oxygen consumption $\left(\mathrm{VO}_{2}\right)$; anaerobic threshold (AT); device function; and evidence of structural valve deterioration, including stent fracture. Safety outcomes were device malfunction; arrhythmia; coronary compression; neurologic impairment; conduit/RVOT rupture; stent dislocation/THV dislocation; bleeding complications; need for surgical correction; endocarditis of the implanted valve; and any cardiovascular events, including death, myocardial infarction, coronary compression, pulmonary embolism, and stroke/transient ischemic $\operatorname{attack}(T I A)$.

\subsection{Data collection}

Authors collectively designed a case report form to accommodate the broadest possible spectrum of clinical situations in which PPVI may be indicated. Data collection was paper-based, with investigators transferring the obtained data (via letter, fax, or email) to the coordinating centre at the Institute for Pharmacology and Preventive Medicine (IPPMed, Cloppenburg, Germany). Double data entry was carried out by data managers to transfer the information to the Pulmonic XT database. 
Follow-up time points were defined as follows: 30 days (post intervention up to and including 30 days), 6 months (more than 30 days and up to and including 6 months), 1 year (more than 6 months and up to and including 1 year), and 2 years (more than 1 years and up to and including 2 years).

\subsection{Statistics}

For categorical variables (e.g. gender) frequency distributions are given. For numerical variables (e.g. patient age) means with standard deviations (SD) and medians with ranges are given. Statistical analysis was performed using SPSS Statistics 23.0 (SPSS, Inc., Chicago, IL).

\section{RESULTS}

A total of eight centres participated in the registry. Five of the 23 approached centres were unresponsive to the invitation to participate, five declined participation, and five did not deliver data. Up until May $31^{\text {st }} 2017$, the 8 participating centres provided data on a total of 46 patients (range 1 to 21 patients per centre). This corresponds to $50.5 \%$ of the 91 patients estimated to have received an implant up to this time point. Follow-up was $89.1 \%$ at day $30(n=41), 65.2 \%$ at 6 months $(n=30)$, $41.3 \%$ at 1 year $(n=19)$, and $41.3 \%$ at 2 years $(n=19)$. Three patients died during the extended followup (>30 days).

\subsection{Patient characteristics}

At baseline, the mean age was 29.0 ( $S D \pm 14.1$ ) years (range 9-64 years, median 27.5 years) and $28.3 \%$ were female (13/46) (Table 1$)$. The majority of patients $(27 / 46 ; 58.7 \%)$ had ToF as the underlying primary diagnosis, followed by 5 patients with truncus arteriosus (10.9\%) and 4 patients who had undergone a Ross Procedure (8.7\%). Of the two patients with simple PS as a primary 


\subsection{Procedural characteristics}

There was a strong preference for the transfemoral access route (93.5\%), with a jugular access route selected for only three patients (6.5\%; Table 2). The RVOT was pre-stented in 42 patients, with 19 being stented before and 22 stented on the day of the procedure (no information on the time of stenting in one patient). The majority received one stent $(69.6 \%)$ and the most frequently chosen stent type was a CP bare stent (38.1\%). Before pre-dilation, the minimal RVOT diameter was 16.6 (SD $\pm 4.6) \mathrm{mm}$, increasing to 22.8 (SD \pm 3.3 ) $\mathrm{mm}$ after pre-dilation. The $26 \mathrm{~mm}$ SAPIEN XT was the most frequently chosen valve size ( $n=26 ; 56.5 \%)$, followed by the $23 \mathrm{~mm}$ valve $(n=10 ; 21.7 \%)$ and $29 \mathrm{~mm}$ valve ( $n=8 ; 17.4 \%)$, with only $4.3 \%(n=2)$ receiving the smallest $20 \mathrm{~mm}$ valve. In $23.9 \%$ of patients (11/46), the SAPIEN XT was implanted into a previously implanted bioprosthesis (Symbion in 3 patients, Mitroflow in 2, Carpentier-Edwards Perimount in 2, and Medtronic in 1, other in 3). In these 11 patients, the principal diagnosis was ToF alone (5 patients), followed by history of Ross Procedure (2), pulmonary atresia with VSD (1) and without VSD (1), truncus arteriosus (1), and pulmonary stenosis (1). Mean total procedural time was $147.8(S D \pm 55.0)$ minutes, with a fluoroscopy time of $38.4(\mathrm{SD} \pm 30.1)$ minutes and a mean contrast volume of $171.5(\mathrm{SD} \pm 134.4) \mathrm{ml}$.

\subsection{Periprocedural and long-term outcomes}

Procedural success, defined as a single valve implanted in the intended location, was 93.5\% (Table 3). An example of a successfully implanted valve can be seen in Supplementary Figure 2. Periprocedural 
complications were transient in one patient, with a significant paravalvular leak that was managed without a need for conversion to surgery but with a new stent and a SAPIEN XT $26 \mathrm{~mm}$ valve. The patient was clinically stable (NYHA class I) at follow-up, with trivial pulmonary regurgitation. In another two patients, conversion to surgery was necessary due to valve dislocation. In a retrospective analysis, valve dislocation occurred due to inadequate measurement of the pre-stented outflow tract, resulting in an inadequate valve size within a large RVOT. No periprocedural mortality occurred.

Three deaths occurred during follow-up, but were not valve-related: one at 3 months due to lifethreatening comorbidities, and the other at 5 months due to multiple organ failure resulting from complications after surgical aortic valve replacement for severe aortic insufficiency, which had already been apparent prior to PPVI.

\subsection{Functional outcomes}

After PPVI, an improvement in heart failure was seen (Table 4). While $38.1 \%$ of patients enrolled in the registry were at NYHA class III-IV prior to intervention, this declined to $13.0 \% 6$ months after the procedure. Accordingly, an improvement of pulmonary and tricuspid regurgitation was noted, with no or trivial pulmonary regurgitation in $92.5 \%$ of patients at follow-up day 30 , and $85.7 \%$ after two years. The peak systolic gradient $\left(4 \mathrm{Vmax}^{2}\right)$ over the pulmonary and tricuspid valves decreased markedly after PPVI; however, peak systolic gradients over the RVOT remained substantially lower than baseline at 2 years. Results regarding oxygen consumption and anaerobic threshold were difficult to interpret owing to small patient numbers. 


\subsection{Haemodynamics}

A significant reduction in the proportion of patients experiencing moderate/severe pulmonary regurgitation was seen following PPVI (5.0\% at day 30 compared to $76.1 \%$ at baseline) which persisted up to 2 years. This marked drop is consistent with that reported in previous studies ${ }^{2-5,7,8}$, and supports the case for the long-term efficacy of PPVI with the SAPIEN XT. Concurrently, the mean peak systolic RVOT gradient at 30 days post-PPVI in the present study had dropped by $29 \mathrm{mmHg}$ relative to baseline. This is similar to the magnitude of post-procedural improvement seen by a number of other studies (reductions of between 18 and $30 \mathrm{mmHg}$ ) ${ }^{2-5,8-10}$, including one solely evaluating PPVI in patients undergoing valve-in-valve procedures. ${ }^{7}$ Of these studies, those assessing long-term hemodynamic outcomes also reported a continued, progressive reduction in this gradient

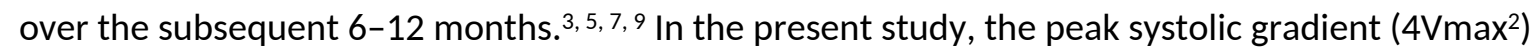
remained markedly lower than the baseline value at all follow-ups. The finding that the mean peak RVOT gradient was $16.4 \mathrm{mmHg}$ at 30 days is particularly encouraging given recent evidence that a post-procedural RVOT gradient below $25 \mathrm{mmHg}$ is associated with longer periods of freedom from intervention ${ }^{10}$, and a reduction in conduit gradient is an independent predictor for increased exercise capacity. ${ }^{11}$ Our findings are therefore consistent with the idea that PPVI results in a marked, sustained improvement in cardiac flow for patients with a range of underlying aetiologies and RVOT 


\subsection{Functional status}

Concurrent with improvement in hemodynamic dysfunction, a large improvement in NYHA class was observed following PPVI, with the proportion of patients in class III or IV falling from $38.1 \%$ to just 9.4\% at day 30. Furthermore, a trend towards an increasing proportion of patients falling within NYHA class I was apparent up to 2 years. In support of our findings, several other studies have also reported a dramatic shift of patients from higher to lower NYHA classes following PPVI, accompanied by a long-term persistence of this finding. ${ }^{3,4,8,10,12}$ The only decline in NYHA class that has been reported was identified as being due to stent fracture or recurrent RVOT obstruction ${ }^{8}$, neither of which was encountered in the present study. Thus, despite limited patient numbers, we can be reasonably confident that PPVI with the SAPIEN XT results in both short- and mid-term improvements in functional status. Future data analysis including a greater number of patients at later follow-ups will help to confirm this.

The increased diameter of the RVOT after PPVI enables a significant increase of cardiac output under exercise conditions, translating into a measurable increase in exercise capacity. On the other hand, in patients with predominant pulmonary regurgitation, PPVI will result in a reduced RV volume, but very often no considerable change in exercise capacity. In our cohort, the majority (35/46) showed moderate / severe pulmonary regurgitation as the leading pathophysiology, therefore no major change in exercise capacity could be anticipated.

\subsection{Periprocedural complications and events}

A high procedural success rate (93.5\%) and low rates of periprocedural complications and adverse events (approximately 6.5\% and 10.9\%, respectively) were observed in the present study. These are 
similar to those reported previously for SAPIEN devices..$^{3,4,12,13}$ In terms of procedural complications, one incident of device malfunction resulting in a significant paravalvular leak that was managed without a need for conversion to surgery and two episodes of valve dislocation (4.4\% of patients) requiring conversion to surgery were observed; in retrospect, these dislocations may have been preventable, and may be attributed to a learning curve. The rate of valve dislocation compares favourably to the rates reported in previous studies by Haas et al. and Kenny et al. using the SAPIEN THV (8.8\% and $13.6 \%$, respectively).$^{3,4}$ In addition, the remaining adverse events reported herein are minimal and included only arrhythmia requiring pacing, drugs, or cardioversion (4 patients). There was however one report of significant bleeding at the groin catheter insertion site. Other authors have previously reported additional complications and events such as transient cerebral plexus palsy, pulmonary haemorrhage, ventricular fibrillation, and stent or THV migration ${ }^{3,4}$; none of which were seen in the current study. Standardisation of complication/event reporting would aid comparisons in future studies. In any case, all events and complications in the present study were successfully resolved without further complications, and the 3 deaths that occurred at $>30$ days post-PPVI were considered unrelated to the procedure or device used. This may lend further evidence as to the safety of the SAPIEN XT.

Stent fracture has been a significant concern for PPVI, though has been more often associated with the Melody valve. ${ }^{2,9,14,15}$ One study reported as much as $18 \%$ of patients experiencing this complication up to one year, even after pre-stenting. ${ }^{16}$ Conversely, studies have consistently reported no stent fractures in patients treated with SAPIEN valves ${ }^{3,4,12,13}$, which was also the case in the present study. This suggests that the SAPIEN XT has the same superior device integrity as previous models and may be preferable to Melody valves in patients at risk of stent fracture, such as those with severely obstructed RVOT conduits. ${ }^{14}$

The high mortality associated with coronary compression following valve deployment in PPVI makes it a particular cause for concern, especially as Morray et al. reported that approximately $5 \%$ of patients are at risk. ${ }^{17}$ In the present study, no patients experienced coronary compression, despite 
the diverse range of underlying diagnoses (including a large number of patients with ToF) and intersubject diversity. This reflects improvements in pre-implantation procedures that have enhanced the safety and predictability of PPVI. Future studies to identify patients most at risk of developing arrhythmias would further improve the safety outcomes of PPVI.

\subsection{Generations of Edwards SAPIEN valves}

The number of patients for whom PPVI is deemed appropriate has been severely limited by both anatomical substrate and the restricted availability of heart valve sizes. ${ }^{6}$ In a study by Lurz et al. in $2008,5 \%$ of patients did not meet the morphological criteria for PPVI due to incompatible RVOT dimensions. ${ }^{15}$ In the present study, the $26 \mathrm{~mm}$ valve was most frequently used. This size was already available in the previous SAPIEN range and was recognised as a welcome extension to the Melody valve, which had previously only been expandable to sizes of $18-22 \mathrm{~mm} .{ }^{4}$ However, $17.4 \%(8 / 46)$ of patients in the present study benefitted from the availability of a $29 \mathrm{~mm}$ valve, a newly available size with the SAPIEN XT range. This confirms the potential for larger valves to permit PPVI in a significant number of patients with larger outflow tracts, as was previously suggested by Demkow et al. ${ }^{13}$ On the other hand, 2 patients were treated with a $20 \mathrm{~mm}$ valve, thereby extending the potential use even to patients with smaller RVOTs. Further extension of the available valve sizes may open up the opportunity for PPVI to even more patients in future.

The most recent SAPIEN 3 valve has recently received FDA approval for the aortic position. This valve is also available in 23,26 , and $29 \mathrm{~mm}$ sizes, and offers further potential advantages, such as an outer skirt for minimisation of paravalvular leakage, and an improved frame design to allow smaller crimping and higher radial strength. A recent study comparing the SAPIEN 3 and SAPIEN XT THVs for transcatheter implantation in the aortic position has reported that the newest model is associated with reduced platelet activation and a lesser degree of aortic regurgitation. ${ }^{18}$ Future real-world studies will examine its potential benefits in the pulmonary position (NCT02777892). 


\subsection{Study limitations}

The number of patients enrolled in this registry is small. This is a commonly encountered limitation in studies assessing PPVI, which is due to the relative novelty of the procedure and the limited availability of patients. This was further complicated in the present study by the reluctance of sites to participate.

There is presently little registry data available regarding the long-term effects of PPVI with the SAPIEN XT on haemodynamics and functionality. Therefore, the sustainability of the initial positive results is uncertain. However, our findings compare well to earlier published results of PPVI with the SAPIEN valve ${ }^{2-5}$, suggesting validity. The on-going collection of data at later time points will help to clarify longitudinal trends in the present study, while future studies with larger cohorts will add value to our findings.

As a largely retrospective study, uncertainty over the reliability of procedural data is an inherent limitation, and not all data was available for each patient. The latter was particularly evident regarding exercise capacities. However, this problem is unavoidable in a real-world setting as the relative rarity of patients meeting entry requirements would result in either an excessively long prospective trial period or insufficient patient numbers. Therefore, future studies when the SAPIEN $\mathrm{XT}$ is more widely utilised for PPVI are necessary to investigate aspects such as improvements in oxygen consumption.

The observational nature of the present study led to a lack of PPVI procedure standardisation throughout the different centres, implying that results may have been influenced by the various management approaches. Further, because patients were retrospectively documented in this registry, there were no information captured on patients excluded because of the proximity of the coronary arteries to the RVOT. However, the observational design may offer several potential 


\section{CONCLUSIONS}

In those patients we were able to document, the SAPIEN XT had a good safety profile and a high level of efficacy in terms of haemodynamic and functional improvement. This appears at least comparable to the previous SAPIEN valve, with a potentially reduced complication rate. The availability of an additional valve size for implantation in the pulmonary position has allowed PPVI to be successfully carried out in patients with a larger conduit diameter for whom the procedure would otherwise have been impossible. Continued data collection and initiation of larger registries in future will add weight to our findings.

\section{AUTHOR CONTRIBUTIONS}

All authors, led by Nikolaus A. Haas (NH), Peter Bramlage (PB), and Michael Mullen (MM), were involved in the conception and design of the study. PB drafted the manuscript, and all authors have revised the article for important intellectual content. All authors gave final approval of the version to be submitted.

\subsection{Principal investigators}

Nikolaus A. Haas (Munich, Germany; previously Bad Oeynhausen, Germany), Michael Mullen (London, UK), Peter Bramlage (Cloppenburg, Germany) 


\subsection{Centres with enrolled patients (Investigators)}

Bad Oeynhausen, Germany 21 patients (Nikolaus A. Haas); Vancouver, Canada 7 pts (Ronald Giacomo Carere); Zürich, Switzerland 5 pts (Oliver Kretschmar); Toronto, Canada 5 pts (Eric Horlick); Munich, Germany 3 pts (Peter Ewert); Quebec, Canada 2 pts (Josep Rodés-Cabau); Gent, Belgium 2 pts (Daniël de Wolf), Gasthuisberg, Leuven, Belgium 1 patient (Marc Gewillig)

\section{ACKNOWLEDGEMENTS}

Helen Sims (IPPMed Barcelona) provided editorial support during the preparation of this manuscript. Andrea Gansz (IPPMed Cloppenburg) managed the conduct of the project.

\section{REFERENCES}

1. Bonhoeffer P, Boudjemline Y, Saliba Z, Merckx J, Aggoun Y, Bonnet D, Acar P, Le Bidois J, Sidi

D, Kachaner J. Percutaneous replacement of pulmonary valve in a right-ventricle to pulmonary-artery prosthetic conduit with valve dysfunction. Lancet 2000;356(9239):1403-1405.

2. Eicken A, Ewert P, Hager A, Peters B, Fratz S, Kuehne T, Busch R, Hess J, Berger F. Percutaneous pulmonary valve implantation: two-centre experience with more than 100 patients. Eur Heart J 2011;32(10):1260-1265.

3. Kenny D, Hijazi ZM, Kar S, Rhodes J, Mullen M, Makkar R, Shirali G, Fogel M, Fahey J, Heitschmidt MG, Cain C. Percutaneous implantation of the Edwards SAPIEN transcatheter heart valve for conduit failure in the pulmonary position: early phase 1 results from an international multicenter clinical trial. J Am Coll Cardiol 2011;58(21):2248-2256. 
4. Haas NA, Moysich A, Neudorf U, Mortezaeian H, Abdel-Wahab M, Schneider H, De Wolf D, Petit J, Narayanswami S, Laser KT, Sandica E. Percutaneous implantation of the Edwards SAPIEN() pulmonic valve: initial results in the first 22 patients. Clin Res Cardiol 2013;102(2):119-128.

5. Chowdhury SM, Hijazi ZM, Rhodes J, Kar S, Makkar R, Mullen M, Cao QL, King L, Akin J, Shirali G. Early echocardiographic changes after percutaneous implantation of the Edwards SAPIEN transcatheter heart valve in the pulmonary position. Echocardiography 2013;30(7):786-793. 6. Ansari MM, Cardoso R, Garcia D, Sandhu S, Horlick E, Brinster D, Martucci G, Piazza N. Percutaneous Pulmonary Valve Implantation: Present Status and Evolving Future. J Am Coll Cardiol 2015;66(20):2246-2255.

7. Asoh K, Walsh M, Hickey E, Nagiub M, Chaturvedi R, Lee KJ, Benson LN. Percutaneous pulmonary valve implantation within bioprosthetic valves. Eur Heart J 2010;31(11):1404-1409. 8. McElhinney DB, Hellenbrand WE, Zahn EM, Jones TK, Cheatham JP, Lock JE, Vincent JA. Shortand medium-term outcomes after transcatheter pulmonary valve placement in the expanded multicenter US melody valve trial. Circulation 2010;122(5):507-516.

9. Vezmar M, Chaturvedi R, Lee KJ, Almeida C, Manlhiot C, McCrindle BW, Horlick EM, Benson LN. Percutaneous pulmonary valve implantation in the young 2-year follow-up. JACC Cardiovasc Interv 2010;3(4):439-448.

10. Cheatham JP, Hellenbrand WE, Zahn EM, Jones TK, Berman DP, Vincent JA, McElhinney DB. Clinical and hemodynamic outcomes up to 7 years after transcatheter pulmonary valve replacement in the US melody valve investigational device exemption trial. Circulation 2015;131(22):1960-1970. 11. Lurz P, Giardini A, Taylor AM, Nordmeyer J, Muthurangu V, Odendaal D, Mist B, Khambadkone S, Schievano S, Bonhoeffer P, Derrick G. Effect of altering pathologic right ventricular loading conditions by percutaneous pulmonary valve implantation on exercise capacity. Am J Cardiol 2010;105(5):721-726.

12. Wilson WM, Benson LN, Osten MD, Shah A, Horlick EM. Transcatheter Pulmonary Valve Replacement With the Edwards Sapien System: The Toronto Experience. JACC Cardiovasc Interv 2015;8(14):1819-1827. 
13. Demkow M, Ruzyllo W, Biernacka EK, Kalinczuk L, Spiewak M, Kowalski M, Sitkowska E, Kusmierczyk M, Rozanski J, Banas S, Chmielak Z, Hoffman P. Percutaneous Edwards SAPIEN() valve implantation for significant pulmonary regurgitation after previous surgical repair with a right ventricular outflow patch. Catheter Cardiovasc Interv 2014;83(3):474-481.

14. McElhinney DB, Cheatham JP, Jones TK, Lock JE, Vincent JA, Zahn EM, Hellenbrand WE. Stent fracture, valve dysfunction, and right ventricular outflow tract reintervention after transcatheter pulmonary valve implantation: patient-related and procedural risk factors in the US Melody Valve Trial. Circ Cardiovasc Interv 2011;4(6):602-614.

15. Lurz P, Coats L, Khambadkone S, Nordmeyer J, Boudjemline Y, Schievano S, Muthurangu V, Lee TY, Parenzan G, Derrick G, Cullen S, Walker F, Tsang V, Deanfield J, Taylor AM, Bonhoeffer P. Percutaneous pulmonary valve implantation: impact of evolving technology and learning curve on clinical outcome. Circulation 2008;117(15):1964-1972.

16. Nordmeyer J, Lurz P, Khambadkone S, Schievano S, Jones A, McElhinney DB, Taylor AM, Bonhoeffer P. Pre-stenting with a bare metal stent before percutaneous pulmonary valve implantation: acute and 1-year outcomes. Heart 2011;97(2):118-123.

17. Morray BH, McElhinney DB, Cheatham JP, Zahn EM, Berman DP, Sullivan PM, Lock JE, Jones TK. Risk of coronary artery compression among patients referred for transcatheter pulmonary valve implantation: a multicenter experience. Circ Cardiovasc Interv 2013;6(5):535-542.

18. Fateh-Moghadam S, Voesch S, Htun P, Jorbenadze R, Geisler T, Gawaz M, Bocksch W. Platelet activation is less enhanced in the new balloon expandable Edwards Sapien 3 valve compared to its predecessor model (Edwards Sapien XT). Thromb Haemost 2016;115(1):109-116. 


\section{TABLES}

Table 1: Patient characteristics

$\mathrm{n} / \mathrm{N}(\%) /$ mean $\pm \mathrm{SD} /$ median (range)

\begin{tabular}{|c|c|}
\hline \multirow[t]{2}{*}{ Age [years] } & $29.0 \pm 14.1$ \\
\hline & $27.5(9-64)(N=46)$ \\
\hline Female gender & $13 / 46(28.3)$ \\
\hline \multirow[t]{2}{*}{ Weight $[\mathrm{kg}]$} & $71.3 \pm 20.5$ \\
\hline & $68.7(22-110)(N=46)$ \\
\hline \multirow[t]{2}{*}{ Height $[\mathrm{cm}]$} & $167.8 \pm 13.8$ \\
\hline & $172.5(130-189)(\mathrm{N}=46)$ \\
\hline Prior endocarditis & $4 / 43(9.3)$ \\
\hline \multicolumn{2}{|l|}{ Underlying diagnosis } \\
\hline ToF & $27 / 46(58.7)$ \\
\hline Pulmonary atresia with VSD & $3 / 46(6.5)$ \\
\hline Pulmonary atresia without VSD & $3 / 46(6.5)$ \\
\hline Truncus arteriosus & $5 / 46(10.9)$ \\
\hline $\mathrm{Hx}$ of Ross Procedure & $4 / 46(8.7)$ \\
\hline TGA & $2 / 46(4.3)$ \\
\hline Pulmonary stenosis & $2 / 46(4.3)$ \\
\hline \multicolumn{2}{|l|}{ RVOT anatomy prior to valve implantation } \\
\hline Native RVOT / PS & $5 / 46(10.9)$ \\
\hline Transannular patch & $6 / 46(13.0)$ \\
\hline Homograft & $8 / 46(17.4)$ \\
\hline Stentless xenograft & $16 / 46(34.8)$ \\
\hline Others (Carpentier-Edwards, Hancock etc.) & $11 / 46(23.9)$ \\
\hline
\end{tabular}

Legend: $n$, number of patients with variable; $N$, number of patients with data available; ToF, Tetralogy of Fallot; TGA, Transposition of the great arteries; DORV, double-outlet right ventricle; RVOT, right ventricular outflow tract; PS, pulmonary stenosis; SD, standard deviation 
Table 2: Procedural characteristics

$43 / 46(93.5)$

Jugular

$3 / 46(6.5)$

RVOT pre-stenting

Stent placed at the time of the procedure

$22 / 45(48.9)$

Stent placed before day of procedure

$19 / 45(42.2)$

Number of stents implanted

0

1

2

Type of stent

$\mathrm{CP}$ bare stent

$16 / 42(38.1)$

$\mathrm{CP}$ covered stent

$10 / 42(23.8)$

Andramed

$10 / 42(23.8)$

Other

$6 / 42(14.3)$

Minimal diameter before pre-dilation [mm] $16.6 \pm 4.6$

$17.0(6-25)(N=37)$

Minimal diameter after pre-dilation [mm]

$22.8 \pm 3.3$

$23.0(11-28)(\mathrm{N}=34)$

SAPIEN XT THV size implanted

$20 \mathrm{~mm}$

$2 / 46(4.3)$

$23 \mathrm{~mm}$

$10 / 46(21.7)$

$26 \mathrm{~mm}$

$26 / 46(56.5)$

$29 \mathrm{~mm}$

$8 / 46(17.4)$

Valve in valve (previously implanted bioprothesis)

$11 / 46(23.9)$

Length of procedure [min]

$147.8 \pm 55.0$

$139.5(45-291)(\mathrm{N}=44)$

Fluoroscopy time [min]

$38.4 \pm 30.1$

$33.5(5.0-113.0)(\mathrm{N}=40)$

Contrast volume $[\mathrm{ml}]$

$171.5 \pm 134.4$

$129.5(25-470)(\mathrm{N}=42)$

Legend: $\mathrm{n}$, number of patients with variable; $\mathrm{N}$, number of patients with data available; RVOT, right ventricular outflow tract; $\mathrm{CP}$, Cheatham Platinum; SD, standard deviation 
Table 3: Periprocedural outcomes

\begin{tabular}{lc}
\hline & $\mathrm{n} / \mathrm{N}(\%)$ \\
\hline $\begin{array}{l}\text { Procedural success } \\
\text { Procedural complications }\end{array}$ & $43 / 46(93.5)$ \\
$\quad$ Device malfunction & $1 / 46(2.2)$ \\
$\quad$ Dislocation of valve during implantation requiring & \\
$\quad$ subsequent surgical intervention & $2 / 46(4.4)$ \\
Procedural adverse events & \\
Arrhythmia with pacing, drugs or cardioversion & $4 / 45(8.9)$ \\
Myocardial infarction & $0 / 46(0.0)$ \\
Pulmonary embolism & $0 / 46(0.0)$ \\
Rupture requiring emergency stenting or surgery & $0 / 46(0.0)$ \\
Coronary compression & $0 / 46(0.0)$ \\
Significant bleeding & $1 / 46(2.2)$ \\
Significant neurologic impairment & $0 / 46(0.0)$ \\
Periprocedural death & $0 / 46(0.0)$
\end{tabular}

Legend: $n$, number of patients with variable; $N$, number of patients with data available; SD, standard deviation. *Defined as single valve implanted in intended location. 
Table 4: Functional outcome after PPVI

\begin{tabular}{|c|c|c|c|c|c|}
\hline & Baseline & Day 30 & Month 6 & Year 1 & Year 2 \\
\hline \multicolumn{6}{|l|}{ NYHA class } \\
\hline Class I & $4 / 42(9.5)$ & $20 / 32(62.5)$ & $15 / 23(65.2)$ & 10/14 (71.4) & $9 / 13(69.2)$ \\
\hline Class II & $22 / 42(52.4)$ & $9 / 32(28.1)$ & $5 / 23(21.7)$ & $4 / 14(28.6)$ & $1 / 13(7.7)$ \\
\hline Class III & $15 / 42(35.7)$ & $2 / 32(6.3)$ & $2 / 23(8.7)$ & $0 / 14(0.0)$ & $3 / 13(23.1)$ \\
\hline Class IV & $1 / 42(2.4)$ & 1/32 (3.1) & $1 / 23(4.3)$ & $0 / 14(0.0)$ & $0 / 13(0.0)$ \\
\hline $\begin{array}{l}\text { Peak systolic gradient over RVOT } \\
{[\mathrm{mmHg}]}\end{array}$ & $\begin{array}{c}45.2 \pm 21.3 \\
(N=34)\end{array}$ & $\begin{array}{l}16.4 \pm 8.0 \\
(N=26)\end{array}$ & $\begin{array}{l}20.5 \pm 8.1 \\
(N=15)\end{array}$ & $\begin{array}{c}14.7 \pm 9.9 \\
(N=6)\end{array}$ & $\begin{array}{c}26.1 \pm 10.6 \\
(N=10)\end{array}$ \\
\hline \multicolumn{6}{|l|}{ Pulmonary regurgitation } \\
\hline None/trivial & $3 / 46(6.5)$ & $37 / 40(92.5)$ & $27 / 29(93.3)$ & $13 / 18(72.2)$ & $12 / 14(85.7)$ \\
\hline Mild & $8 / 46(17.4)$ & $1 / 40(2.5)$ & $1 / 29(3.4)$ & $3 / 18(16.7)$ & $2 / 14(14.3)$ \\
\hline Moderate & $8 / 46(17.4)$ & $2 / 40(5.0)$ & $1 / 29(3.4)$ & $2 / 18(16.7)$ & $0 / 15(0.0)$ \\
\hline Severe & $27 / 46(58.7)$ & $0 / 40(0.0)$ & $0 / 29(0.0)$ & $0 / 18(0.0)$ & 0/15 (0.0) \\
\hline $\begin{array}{l}\text { RVSP across tricuspid valve } \\
{[\mathrm{mmHg}]}\end{array}$ & $\begin{array}{l}59.6 \pm 19.0 \\
(N=38)\end{array}$ & $\begin{array}{l}35.0 \pm 9.3 \\
(N=33)\end{array}$ & $\begin{array}{c}35.2 \pm 15.1 \\
(N=20)\end{array}$ & $\begin{array}{l}33.8 \pm 9.8 \\
(N=12)\end{array}$ & $\begin{array}{c}32.6 \pm 12.7 \\
(N=13)\end{array}$ \\
\hline \multicolumn{6}{|l|}{ Tricuspid regurgitation } \\
\hline None/trivial & $16 / 46(34.8)$ & $24 / 39(61.5)$ & $10 / 30(33.3)$ & $5 / 17(29.4)$ & 6/17 (35.3) \\
\hline Mild & $22 / 46(47.8)$ & $10 / 39(25.6)$ & $16 / 30(53.3)$ & $10 / 17(58.8)$ & $9 / 17(52.9)$ \\
\hline Moderate & $6 / 46(13.0)$ & $4 / 39(10.3)$ & $3 / 30(10.0)$ & $2 / 17(11.8)$ & 2/17 (11.8) \\
\hline Severe & $2 / 46(4.3)$ & $1 / 39(2.6)$ & $1 / 30(3.3)$ & 0/17 (0.0) & $0 / 17(0.0)$ \\
\hline $\begin{array}{l}\text { Peak oxygen consumption } \\
{\left[\mathrm{ml} \mathrm{O}_{2} / \mathrm{min} / \mathrm{kg} \text { bodyweight }\right]}\end{array}$ & $\begin{aligned} 30.0 & \pm 25.6 \\
(\mathrm{~N} & =9)\end{aligned}$ & - & $\begin{array}{c}15.8 \pm 7.5 \\
(N=4)\end{array}$ & $\begin{array}{c}26.5 \pm 7.5 \\
(N=6)\end{array}$ & $\begin{array}{c}22.4 \pm 8.2 \\
(N=9)\end{array}$ \\
\hline
\end{tabular}




\section{SUPPLEMENTARY FIGURE LEGENDS}

Supplementary Figure 1: Native RVOT after balloon dilatation of a native and severe PS. Initially severe Pulmonary regurgitation. Prestenting performed with an Andrastent followed by implantation of a $26 \mathrm{~mm}$ SAPIEN XT valve.

Supplementary Figure 2: Edwards SAPIEN XT transcatheter heart valve for PPVI. 


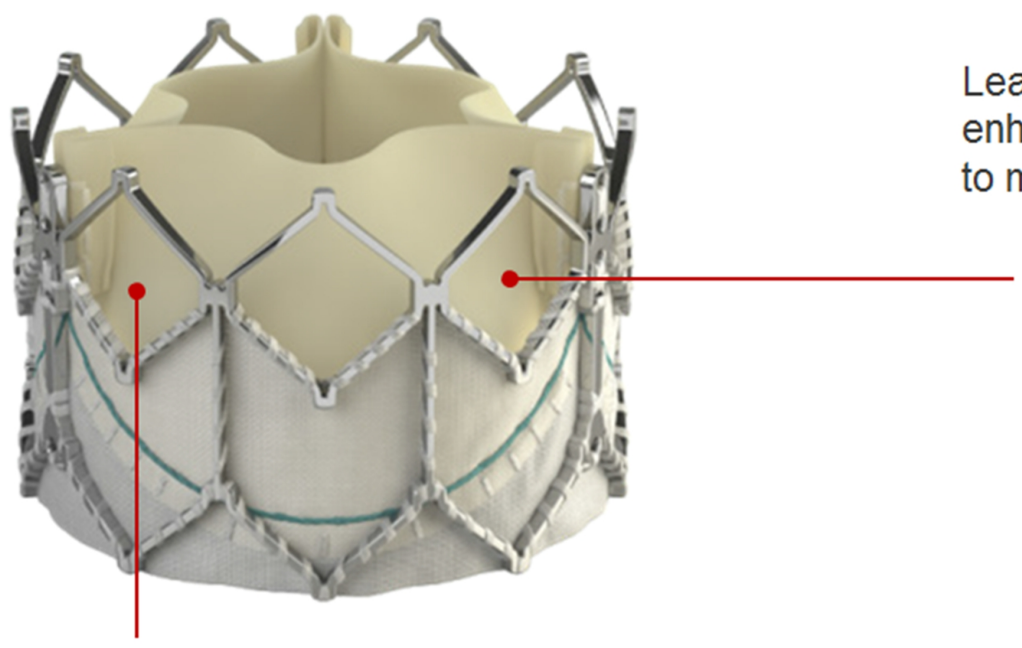

Leaflet design and matching enhance stress distribution

to maximize leaflet durability

The Carpentier-Edwards ThermaFix process

is intended to minimize the risk of calcification
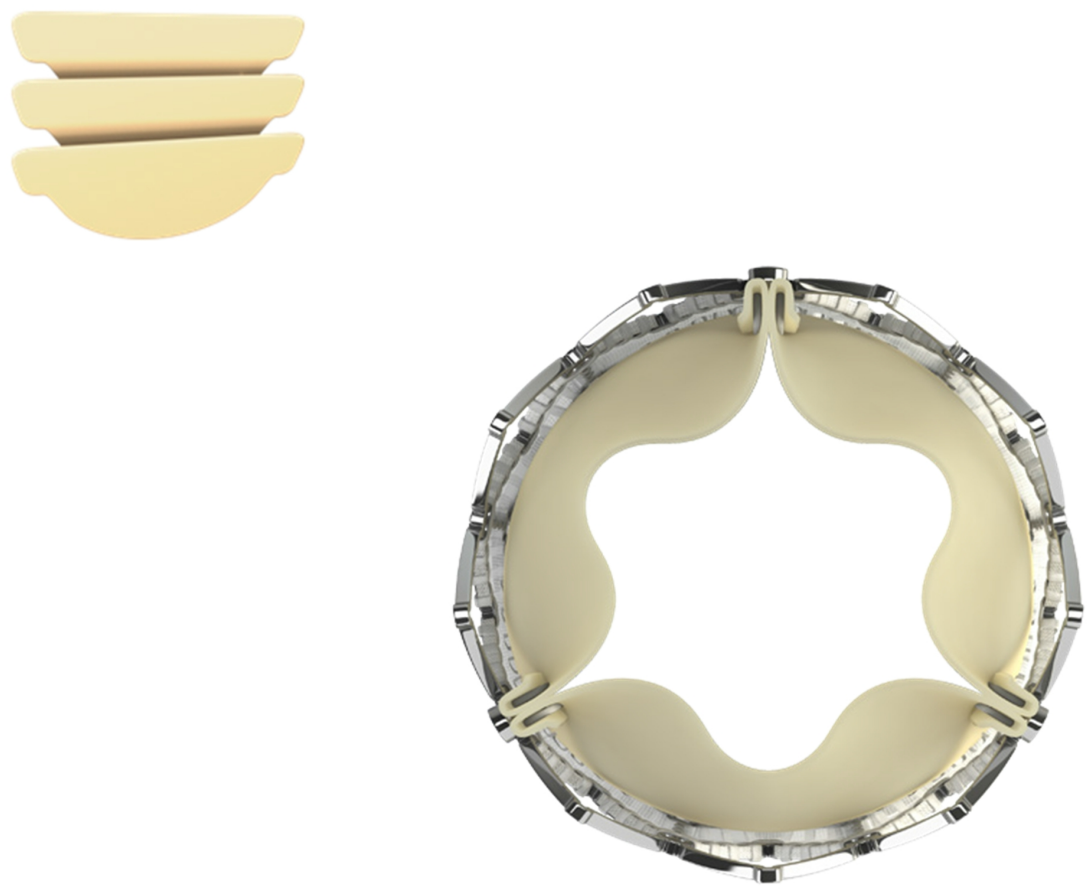

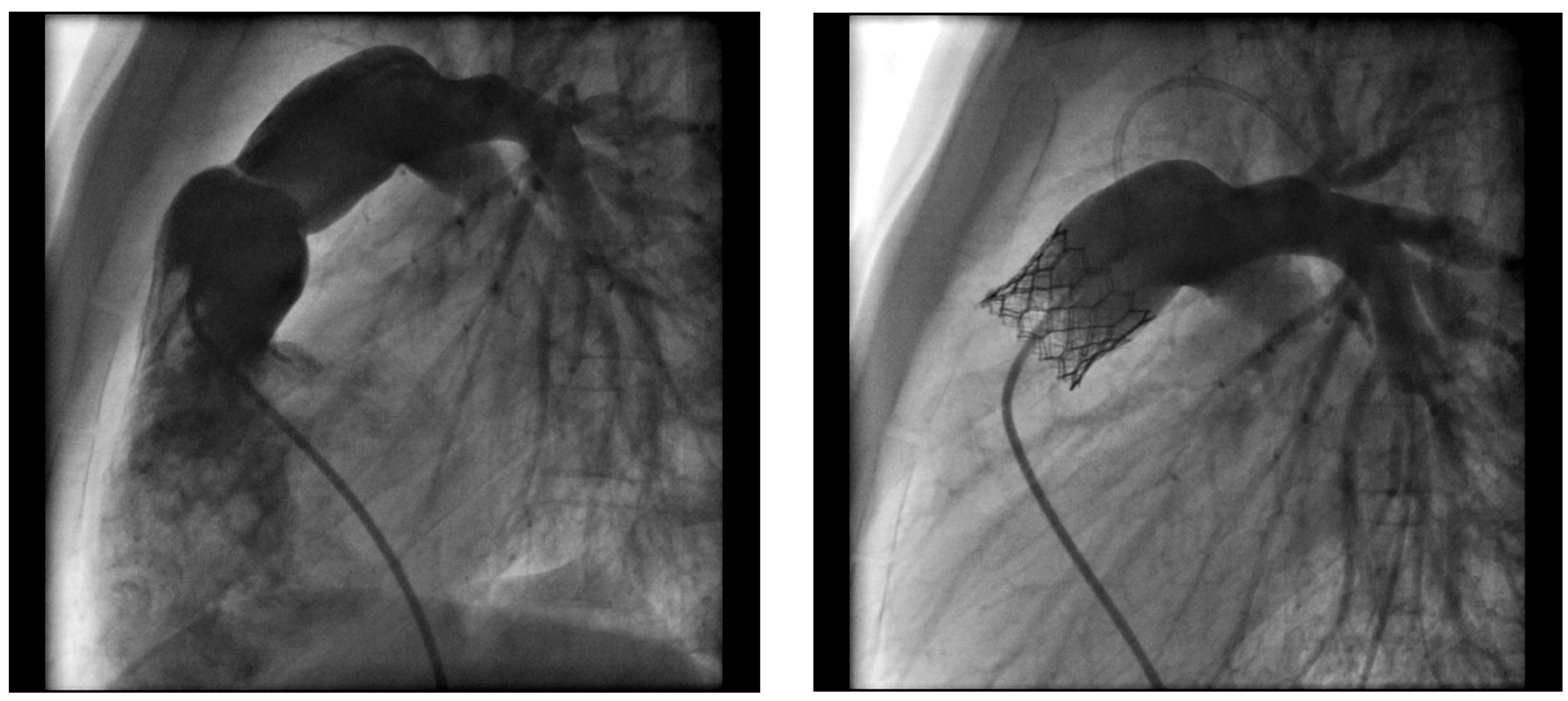
Supplementary Table 1: Comparison of SAPIEN XT Balloon-Expandable Transcatheter Heart Valve (Model 9300TFX) Parameters

\begin{tabular}{|c|c|c|c|c|}
\hline & SAPIEN XT $(20 \mathrm{~mm})$ & SAPIEN XT (23 mm) & SAPIEN XT (26 mm) & SAPIEN XT (29 mm) \\
\hline & $\frac{20 \mathrm{~mm}}{(13)^{13.5 \mathrm{~mm}}}$ & $23 \mathrm{~mm}$ & $26 \mathrm{~mm}$ & $100^{19.1 \mathrm{~mm}}$ \\
\hline Tissue Thickness & $0.3-0.4$ & $0.3-0.4 \mathrm{~mm}$ & $0.3-0.4 \mathrm{~mm}$ & $0.4-0.5 \mathrm{~mm}$ \\
\hline Frame height (expanded) & $13.5 \mathrm{~mm}$ & $14.3 \mathrm{~mm}$ & $17.2 \mathrm{~mm}$ & $19.1 \mathrm{~mm}$ \\
\hline Frame height (crimped) & $16 \mathrm{~mm}$ & $17 \mathrm{~mm}$ & $20 \mathrm{~mm}$ & $22 \mathrm{~mm}$ \\
\hline Frame shortening (deployment) & $2 \mathrm{~mm}$ & $3 \mathrm{~mm}$ & $3 \mathrm{~mm}$ & $3 \mathrm{~mm}$ \\
\hline Fabric Skirt Height & $6 \mathrm{~mm}$ & $6 \mathrm{~mm}$ & $8 \mathrm{~mm}$ & $11 \mathrm{~mm}$ \\
\hline Delivery system & NovaFlex+ & NovaFlex+ & NovaFlex+ & NovaFlex+ \\
\hline Delivery system volume & $11 \mathrm{ml}$ & $17 \mathrm{ml}$ & $22 \mathrm{ml}$ & $33 \mathrm{ml}$ \\
\hline Rates burst pressure & $7 \mathrm{~atm}$ & $7 \mathrm{~atm}$ & $7 \mathrm{~atm}$ & $7 \mathrm{~atm}$ \\
\hline
\end{tabular}




\begin{tabular}{|c|c|c|c|c|}
\hline eSheath profile (internal diameter, & $16-\mathrm{F}$ & $16-\mathrm{F}$ & $18-\mathrm{F}$ & $20-\mathrm{F}$ \\
\hline unexpanded) & $(5.3 \mathrm{~mm})$ & $(5.3 \mathrm{~mm})$ & $(5.9 \mathrm{~mm})$ & $(6.6 \mathrm{~mm})$ \\
\hline eSheath profile (outer diameter, & 6.7 & $6.7 \mathrm{~mm}$ & $7.2 \mathrm{~mm}$ & $8.0 \mathrm{~mm}$ \\
\hline \multicolumn{5}{|l|}{ unexpanded) } \\
\hline Guidewire Compatibility & $0.035^{\prime \prime}$ & $0.035^{\prime \prime}$ & $0.035^{\prime \prime}$ & $0.035^{\prime \prime}$ \\
\hline Minimum Access Vessel Diameter & $6.0 \mathrm{~mm}$ & $6.0 \mathrm{~mm}$ & $6.5 \mathrm{~mm}$ & $7.0 \mathrm{~mm}$ \\
\hline
\end{tabular}

Legend: None 